\title{
Online health forums: the role of online support for people living with breast cancer
}

\author{
Sarah Hargreaves ${ }^{*, 1} \&$ Peter A Bath**,1 \\ ${ }^{1}$ Information School, University of Sheffield, Sheffield, S1 4DP, UK \\ *Authors for correspondence: sarah.hargreaves@sheffield.ac.uk \\ **Authors for correspondence: p.a.bath@sheffield.ac.uk
}
"Forum users may form strong bonds with other people on the forum and can gain great benefit from belonging and being part of a BC community"

First draft submitted: 27 March 2019; Accepted for publication: 29 March 2019; Published online: 21 August 2019

Keywords: breast cancer $\bullet$ online health forums $\bullet$ support

New developments in technology have the potential to change experiences of living with breast cancer (BC). Our project, 'A Shared Space and a Space for Sharing', explored people's experiences of interacting with an online health forum $(\mathrm{OHF}$ ) provided by the UK-based charity, Breast Cancer Care (BCC). This editorial is based on findings from this study, from research literature, from knowledge gained from working with $\mathrm{BCC}$ to develop resources, and by running engagement events for the public and health professionals.

There are growing numbers of OHFs providing opportunity for people living with health conditions to connect with other people sharing similar experiences and support each other [1]. OHFs (also known as online communities, discussion groups, etc.) are, in essence, support groups accessible via the Web, providing virtual spaces in which people living with, or affected by $\mathrm{BC}$, can converse and share experiences by posting messages online. The format of OHFs varies, some are hosted by health charities, healthcare providers, others have been set up by patients themselves. Conversations may be self directed by patients or facilitated by health professionals. The content may be open to anyone with internet access, or private. Some OHFs are overseen by a 'moderator' who ensures that users abide by forum rules and may also safeguard the well being of users. New developments in technology continue to open up means of connecting patients within this rapidly changing sphere.

Although OHFs differ, at heart they are about connecting people who share similar experiences. Being diagnosed with $\mathrm{BC}$ is a devastating experience [2]. This is often a time of great fear and uncertainty, and can also be very lonely and isolating [2,3]. To find an online community of other people who not only understand and share these feelings but are also going through the challenges of living with $\mathrm{BC}$ themselves can be a relief $[2,4]$. BC OHFs are typically friendly and supportive spaces. Newcomers receive a warm welcome [4] and over time get to know and trust people in the forum [5]; these friendships provide supportive relationships in which to share ups and downs of life with BC and everyday experiences [2,4]. Forum users may form strong bonds with other people on the forum and can gain great benefit from belonging and being part of a $\mathrm{BC}$ community [2,4].

$\mathrm{BC}$ OHFs provide two key types of support: informational and emotional. Being diagnosed with $\mathrm{BC}$ can be both confusing and bewildering, especially in the early days when the language of $\mathrm{BC}$ and clinical terminology is unfamiliar and daunting [4]. OHFs are repositories of posts recounting personal experiences of BC. Posts may encompass broad experiences of $\mathrm{BC}$, from the early days after diagnosis, to shared experiences of people living with or beyond cancer. This knowledge and experience, and the differing perspectives on life with BC, are highly valuable to forum users seeking to make sense of their situation, to inform decision making, and deal with the ongoing challenges of living with $\mathrm{BC}[6,7]$. Peer-to-peer information sharing is more meaningful, coming as it does from people also living with $\mathrm{BC}$ [2]; people may feel more comfortable questioning their peers within the informal anonymous space of the OHF, than health professionals within time-constrained consultations in a clinical setting [1]. Forum users share information on issues that most health professional have no direct experience of, such as, how it really feels when undergoing treatment and what it is like to live with a body changed by surgery or

Future Medicine 
chemotherapy treatment. This first-hand knowledge of the experience of $\mathrm{BC}$ is key to understanding the potential value of $\mathrm{BC}$ OHFs for patients. Information shared within $\mathrm{BC}$ OHF can empower patients, aid decision making, and help patients to regain some control $[1,8,9]$.

There is a high emotional cost to living with $\mathrm{BC}$, and OHFs can provide a space in which to express and unburden feelings. The opportunity to vent and unburden feelings online is valuable to people who find it hard to acknowledge emotional impacts in face-to-face conversations $[1,2,10]$. Participants in our study found that talking to forum friends about how they were feeling was very different to talking to friends, family or health professionals. People in the forum community know all too well what they are talking about. They know what it is like to live with fear, uncertainty, pain and loneliness; they understand and recognize these feelings and are able to acknowledge and validate them [2]. This first-hand, lived experience of BC informs the empathetic support that is often found on OHFs $[2,11]$. Forum users pass on insights from their own experiences to provide caring and supportive responses to other forum users, who may be experiencing a time of great emotional distress. They understand that there are particular times when people may need greater emotional support, such as in the period after diagnosis or while waiting for test results [8]. OHFs can provide timely emotional support and the 24/7 nature of forums mean that there is support for people wakeful and worrying in the early hours of the morning [5]. Forum users learn from each other, they may share coping strategies and offer helpful perspectives in how to deal with periods of anxiety. A culture of reciprocity often occurs within BC OHFs, with forum users both giving and receiving support $[4,5]$.

There are advantages and disadvantages to $\mathrm{BC}$ OHFs. Forums draw in members with a wide range of experiences of $\mathrm{BC}$, enabling people to find someone in a similar situation to themselves, for example, the same stage of life or specific diagnosis $[2,12]$. This opportunity to connect with someone in a similar situation, or at the same stage of treatment, can be particularly helpful: the mirroring of circumstances provides an opportunity for helpful conversations to take place and for friendships to flourish. Forums also provide a space in which to connect people who are different from the general BC population [9], for example, forums may provide a space for men living with $\mathrm{BC}$ to connect and share experiences.

$\mathrm{BC}$ OHFs provide a space to turn to, to share both good and bad news. It can be comforting to be part of an online community, knowing that support is available when needed. This constancy of support is valuable at any stage of a journey with BC. OHFs can bring people together who are about to start their treatments, so that they can share experiences and provide mutual support [5]. There are growing numbers of people living with or beyond BC. OHFs continue to provide support after treatments have ended, at a time when people may perceive that support from health services, family and friends is falling away [3,13]. This is particularly important for people living with cancer for which there is no cure.

Forums do not focus solely on cancer. Forum users share stories about wider life experiences and everyday life [4,14]. People share jokes and humor. This broader conversation provides the opportunity to escape BC, lighten the mood and to pass the time of day, helping to normalize the experience of living with BC.

However, BC OHFs can also have negative impacts [15]. There may be times when it feels overwhelming to be part of a BC OHF. Problems may seem magnified within the space as users share accounts of upsetting experiences [16]. Some forum users can be insensitive [1], sharing posts without thought for others or even arguing with each other [4]. Such instances are, however, rare; forum users generally act with care and consideration for each other. Forums can be a source of hope and inspiration if users are able to find people sharing a similar diagnosis who are living well [17]. They can also be a place of sorrow; it can be upsetting if someone on the forum becomes very ill, or dies [2,16]. This can be a stark reminder of a person's own vulnerability. A common concern with OHFs is the risk that users may share misleading and inaccurate information. The level of inaccuracy will vary, though a study which assessed the accuracy of posts within a BC OHF found high levels of accuracy [9]. In moderated forums, misinformation may be corrected and often forum users do not accept information at face value, they assess the quality of information that is being shared $[1,5]$.

We end this editorial by exploring in brief how BC OHFs fit within wider healthcare provision by looking at the English context. There is little evidence that the NHS has engaged with OHFs, despite the potential of forums to foster greater self reliance in patients and to provide timely and accessible information and emotional support [18,19]. A key issue may be lack of information, or concerns about potential risks for patients, as health professionals face the challenges of practice within a digital world [20]. With this in mind, we worked with BCC to develop information sheets for health professionals and patients to enable them to make informed and personalised choices about $\mathrm{BC}$ OHFs [15]. Please contact us if you would like copies. 
If this editorial has sparked your interest, you may be interested in viewing a film of our play, 'A Space for Sharing', which is a vivid theatrical portrayal of five (fictional) women who use a BC OHF, and is based on our research findings (www.space4sharingstudy.org).

\section{Author contributions}

Dr Hargreaves and Professor Bath are joint authors of this paper.

\section{Acknowledgments}

The authors thank the people who volunteered to be interviewed and shared their experiences with us. The authors thank Breast Cancer Care and the Motor Neurone Disease Association for their support in allowing us access to their online forums and enabling us to recruit forum users to take part in the interviews. We thank Breast Cancer Care for their continued support of our project, and working in partnership with us to develop the information sheets on online health forums.

\section{Note}

The "A Shared Space and A Space for Sharing" project is one of several projects funded through the EMoTICON network (grant no: ES/M00354X/1), which was funded through the following UK cross-council programs: (1) Partnership for Conflict, Crime and Security Research (led by the Economic and Social Research Council), (2) Connected Communities (led by the Arts \& Humanities Research Council), and (3) Digital Economy (led by the Engineering and Physical Sciences Research Council), in partnership with Defence Science and Technology Laboratory and Centre for the Protection of National Infrastructure

\section{Financial \& competing interests disclosure}

The authors have no relevant affiliations or financial involvement with any organization or entity with a financial interest in or financial conflict with the subject matter or materials discussed in the manuscript. This includes employment, consultancies, honoraria, stock ownership or options, expert testimony, grants or patents received or pending, or royalties.

No writing assistance was utilized in the production of this manuscript.

\section{Open access}

This work is licensed under the Attribution-NonCommercial-NoDerivatives 4.0 Unported License. To view a copy of this license, visit http://creativecommons.org/licenses/by-nc-nd/4.0/

\section{References}

1. Allen C, Vassilev I, Kennedy A, Rogers A. Long-term condition self-management support in online communities: a meta-synthesis of qualitative papers. J. Med. Internet Res. 18(3), e61 (2016).

2. Hargreaves S, Bath PA, Duffin S, Ellis J. Sharing and empathy in digital spaces: qualitative study of online health forums for breast cancer and motor neuron disease (amyotrophic lateral sclerosis). J. Med. Internet Res. 20(6), e222 (2018).

3. Macmillan Cancer Support. The rich picture: people living with breast cancer. Understanding the numbers, needs and experiences of people affected by cancer (2017). www.macmillan.org.uk/_images/Breast-Cancer_tcm9-282779.pdf

4. Rubenstein EL. Rituals of introduction and revolving roles: socialization in an online breast cancer community. Libr. Inf. Sci. Res. 37(4), 353-362 (2015).

5. Lovatt M, Bath PA, Ellis J. Development of trust in an online breast cancer forum: a qualitative study. J. Med. Internet Res. 19(5), e175 (2017).

6. Rubenstein EL. 'Things my doctor never told me': bridging information gaps in an online community. Proc. Am. Soc. Inf. Sci. Technol. 49(1), 1-10 (2012).

7. McRoy S, Rastegar-Mojarad M, Wang Y, Ruddy KJ, Haddad TC, Liu H. Assessing unmet information needs of breast cancer survivors: exploratory study of online health forums using text classification and retrieval. JMIR Cancer 4(1), e10 (2018).

8. Chen AT. Exploring online support spaces: using cluster analysis to examine breast cancer, diabetes and fibromyalgia support groups. Patient Educ. Couns. 87(2), 250-257 (2012).

9. Bender JL, Jimenez-Marroquin MC, Ferris LE, Katz J, Jadad AR. Online communities for breast cancer survivors: a review and analysis of their characteristics and levels of use. Support Care Cancer 21(5), 1253-1263 (2013).

10. Eschler J, Pratt W. 'I'm so glad I met you'; designing dynamic collaborative support for young adult cancer survivors. In: Proceedings of the 2017 ACM Conference on Computer Supported Cooperative Work and Social Computing. ACM Press, NY, USA, 1763-1774 (2017).

11. Zhao J, Abrahamson K, Anderson JG, Ha S, Widdows R. Trust, empathy, social identity, and contribution of knowledge within patient online communities. Behav. Inf. Technol. 32(10), 1041-1048 (2013). 
12. Sillence E. Giving and receiving peer advice in an online breast cancer support group. Cyberpsychol. Behav. Soc. Netw. 16(6), 480-485 (2013).

13. Matthews H, Semper H. 'Dropped from the system': the experiences and challenges of long-term breast cancer survivors. J. Adv. Nurs. 73(6), 1355-1365 (2017).

14. Rubenstein EL. 'They are always there for me': the convergence of social support and information in an online breast cancer community. J. Assoc. Inf. Sci. Technol. 66(7), 1418-1430 (2015).

15. Hargreaves S, Bath P, Duffin S. Online health forums Information Sheets. (2018). www.space4sharingstudy.org

16. Ziebland S, Wyke S. Health and illness in a connected world: how might sharing experiences on the internet affect people's health? Milbank Q. 90(2), 219-249 (2012).

17. Vilhauer RP. Perceived benefits of online support groups for women with metastatic breast cancer. Women Health 49(5), 381-404 (2009).

18. Panesar A. Online communities can help the NHS, so why does it ignore them? The Guardian, (2016). www.theguardian.com/healthcare-network/2016/jan/20/online-communities-help-nhs

19. Smith J, Bartlett J, Buck D, Honeyman M. Online support. Investigating the role of public online forums in mental health. Demos (2017). demosuk.wpengine.com/wp-content/uploads/2017/04/Online-Support-Demos-report.pdf

20. Royal College of Nursing. Improving digital literacy (2017). www.rcn.org.uk/professional-development/publications/pub-006129 